\title{
A Novel Autonomous Monitoring System for Distributed Leakage Current Measurements on Outdoor High Voltage Insulators
}

\author{
Nikolaos Mavrikakis ${ }^{1}$, Michalis Kapellakis ${ }^{1}$, Dionisios Pylarinos ${ }^{1}$, and Kiriakos Siderakis ${ }^{1}$
}

\begin{abstract}
The reliable operation of power networks is strongly related to the performance of high voltage insulators. Local weather conditions, environmental pollution, insulator material and high voltage level mainly affect the operation of the installed insulators in high voltage transmission systems. At the last decades, important advance has been made in high voltage insulation by introducing composite materials with innovating advantages comparing to the traditional ceramics, improving the insulators performance even heavy polluted conditions. However, composite materials have limited operation life respecting to their exposure to field ageing mechanisms. Considering all these parameters, the common maintenance techniques of high voltage insulators cannot confront the problem. A parameter which can substantially contribute to the maintenance actions of power utilities is the monitoring of the electrical surface activity of insulators. In this framework, a novel low cost autonomous leakage current monitoring system for high voltage insulators is proposed and gradually constructed in order to respond to the advanced needs of power operators.
\end{abstract}

\footnotetext{
${ }^{1}$ Department of Electrical Engineering

School of Applied Science,

Technological Educational Institute of Crete

Stauromenos, GR71004, tel: +302810-379231, Heraklion,

Greece

(e-mail: mavrikakisnikos@gmail.com)
}

\author{
Keywords \\ Leakage current, monitoring system, insulators, outdoor
}

\section{Acknowledgement}

This work was supported by the POLYDIAGNO research project (code: 11SYN-7-1503) which is a research project implemented through the Operational Program "Competitiveness and Entrepreneurship", Action "Cooperation 2011" and is co-financed by the European Union (European Regional Development Fund) and Greek national funds (National Strategic Reference Framework 2007 - 2013).

\section{Introduction}

The integrity and service efficiency of high voltage insulating systems is critical for the performance and reliability of electric power networks. Considering that in such systems the majority of the installations are outdoor, the action of various environmental parameters, in combination with the electrical and mechanical stress applied may result to a considerable deterioration and even failure of the insulating system. In the case of outdoor high voltage insulators, the primary environmental action is known as insulators pollution and may considerably contribute to the number of failures due in many systems worldwide [1-2]. Such a condition cannot be acceptable considering the requirements valid today, as far as the levels of power quality is concerned and the introduction of distributed generation.

Therefore many methods have been implemented in order to confront the problem, with advantages and disadvantages in each case [3-8]. What is evident in all these maintenance methods is that they cannot completely

This is an Open Access article distributed in accordance with the Creative Commons Attribution Non Commercial (CC-BY-NC-ND 4.0) license, which permits others to copy or share the article, provided original work is properly cited and that this is not done for commercial purposes. Users may not remix, transform, or build upon the material and may not distribute the modified material (http://creativecommons.org/licenses/by-nc/4.0/) 
solve the problem and therefore monitoring is required. Furthermore the common parameter that can be implemented to evaluate all, is the presence of surface electrical activity. Being able of monitoring this activity, may enable network operators to efficiently decide maintenance actions and thus optimize the network operation. Furthermore leakage current is the best representing indication of this activity, considering both the level and waveform and can be applied in all cases.

Unfortunately, leakage current measurements are quite difficult to implement and usually very expensive. These two are the primary drawbacks for the application of this method. However, the development of data acquisition systems and informatics nowadays, enable the development of low cost monitoring networks, where sensors can be geographically distributed, perform onsite measurements, apply a first level data evaluation and then transfer the useful information to the possible stakeholders by different communication technologies. In this paper the development of a low cost leakage current monitoring system, aiming to become the fundamental cell of a sensor network installed on transmission lines is presented. The system is developed on a low cost data acquisition system, implementing techniques signal analysis techniques, developed especially for the application and is integrated with the necessary peripherals that will enable autonomous operation, within the monitoring network.

\section{Insulator monitoring system}

In order to assess the condition of high voltage insulators in service, leakage current monitoring can be combined with weather data monitoring [9]. Until now the available commercial monitoring devices used in power utilities worldwide are limited in number. According to the experience of Greek power utility, based on the usage of commercial insulator leakage current monitoring devices in service, these devices had the following disadvantages [9-11]:

- High cost

- Poor technical support

- Low scalability

- Limited or any upgrades

- $\quad$ Limited flexibility

These devices are able to monitor only limited number of insulators, process and store predefined type of data without giving the opportunity to users to adapt them according to their demands. Based on the experience gained through the large monitoring projects of Greek power utility at the last years, the following project seems to be the most effective for monitoring of high voltage insulators, contributing to the reliable operation of power networks.

According to the proposed project a number of insulator monitoring kits can be installed on the high voltage towers or substations along the high voltage lines, monitoring both leakage currents and weather conditions (Fig.1). Each stand-alone kit can be connected to the insulator monitoring centre through GSM technology warning for possible network faults in the case of critical leakage currents detection. The insulator monitoring kits will send the acquired data to the insulator monitoring centre which will be installed to the closer substation to the monitored high voltage line. The general purpose is to advance a low-cost, autonomous monitoring system, which can be adapted to the advanced demands of 0power utilities through the user friendly software and the smart transmission data technology.

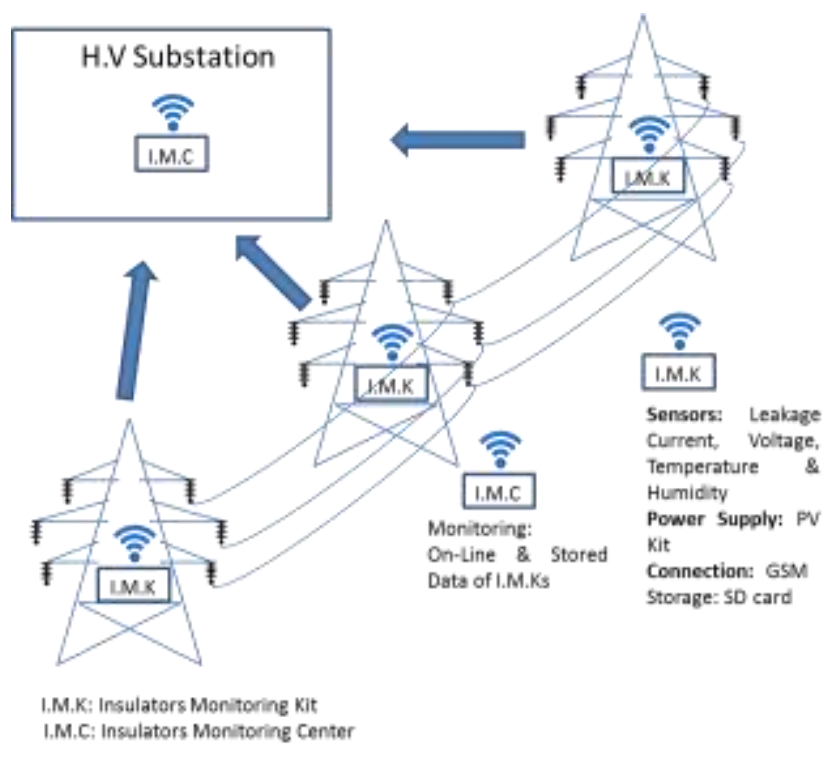

Fig. 1 Insulator Monitoring System

\section{Setup of monitoring device}

The insulator monitoring kit comprises:

- Autonomous power supply

- Weather and current sensors

- Data microcontroller

- $\quad$ Storage device

- GSM module

- Software

Each part of the monitoring device can be easily installed and replaced by users. In addition the open source software gives the advantages of system upgrading without extra charging and software modifying based on 
the customer real demands. The total cost of the monitoring device is estimated to be around a thousand of euros, about 30 times more economical than the commercial systems. Comparing the cost of the monitoring device with that of high voltage tower structure, it is estimated less than $2 \%$ of total cost, which is negligible considering the advantages for the power utility.

\subsection{Autonomous Power Supply}

The autonomous power supply of the monitoring kit is based on a stand-alone photovoltaic kit with 2 days energy storage capacity (Fig. 2). Specifically the photovoltaic module is connected to the charge controller which is responsible for the energy flow from the pv module to the battery and the load. Moreover the charge controller provides the necessary protection to the power supply circuit, avoiding faults caused by overvoltages, overloads, battery's overcharge and deep discharge e.t.c. The power supply of the electronics, such as microcontroller and sensors, is further controlled and stabilized by the power supply microcontroller (Fig. 2, Fig. 3). The aim of power supply controller is to convert and rectify the battery voltage $(12 \mathrm{~V})$ to the nominal electronics' voltage level (5 V).

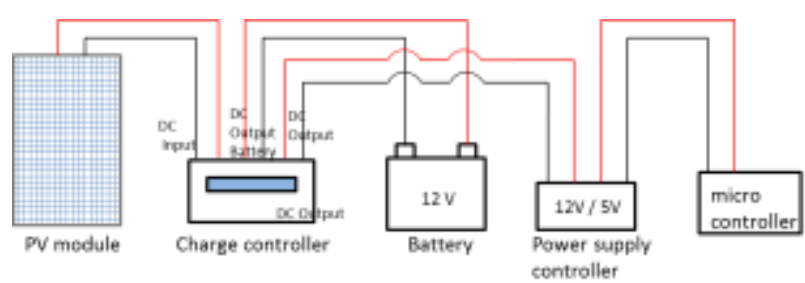

Fig. 2 Autonomous Power Supply

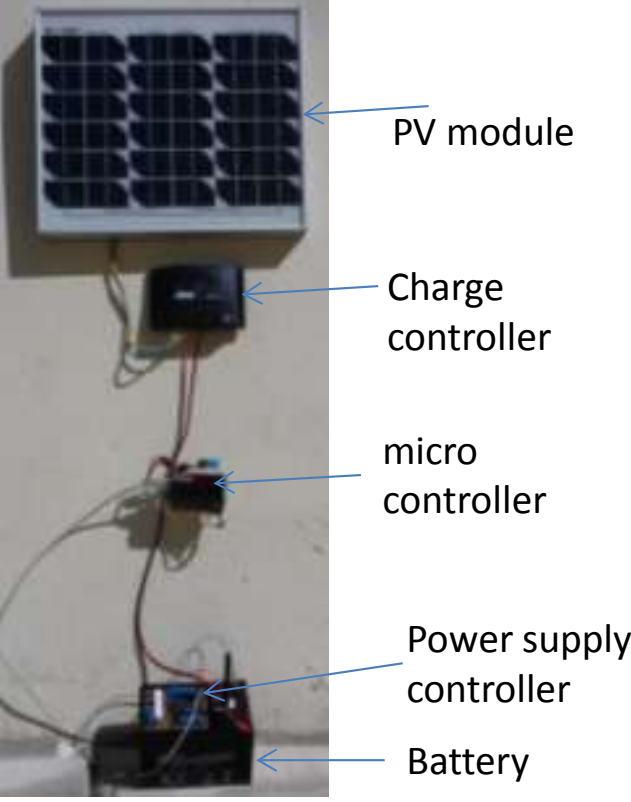

Fig. 3 Experimental setup of autonomous power supply

\subsection{Leakage Current Sensor}

The leakage current of insulators is measured by using a shunt resistor connected in series to insulator ground end fitting (Fig. 4). The selection of shunt resistor gives the ability to measure both alternating currents (AC) and direct currents (DC). The value of leakage current is calculated via Ohm's low $(\mathrm{I}=\mathrm{V} / \mathrm{R})$. The main disadvantages of shunt resistor measurements is the power loss in high current applications. The latter does not occur in leakage current measurements of insulators where the currents, even the case of ceramic insulators, are estimated about some mA under nominal conditions.

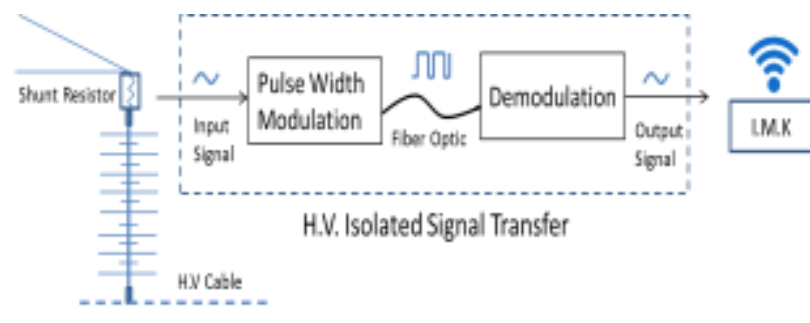

Fig. 4 Leakage current monitoring system

A common disadvantage of measuring systems in high voltage applications is their electric isolation considering the safety of users and systems. For example, if the monitored insulator fails in a high voltage line the high voltage fault will be transferred through the measuring system resulting even to human loss. For this reason, in this study the voltage drop across the shunt resistor is isolated by constructing in our laboratory a fiber optic data transmission system (Fig. 5). The voltage drop of shunt resistor is encoded into a pulsing signal through PWM method (Fig.4). Following the encoded signal is 
transferred through the isolated optical fibre link. The main advantages of this system are the transmission of small electrical signals over long distances with minimum noise, specifically in high voltage applications where the electromagnetic field is considerable, and the electric isolation of the measuring equipment, limiting the damages of possible insulator flashover hazard. At the end of the fibre optic link, the pulse waveform is demodulated to an analog electrical signal and is ended to an analog input of the microprocessor of the insulator monitoring kit. Until now using common commercial electronic non-high speed components, the fiber optic data transmission system is able to transfer analog signals up to $1 \mathrm{kHz}$ and $1 \mathrm{~V}_{\mathrm{pp}}$. Certainly, further developments of this system are able to perform in future upgrading both the frequency and the amplitude of the acquired analog signal.

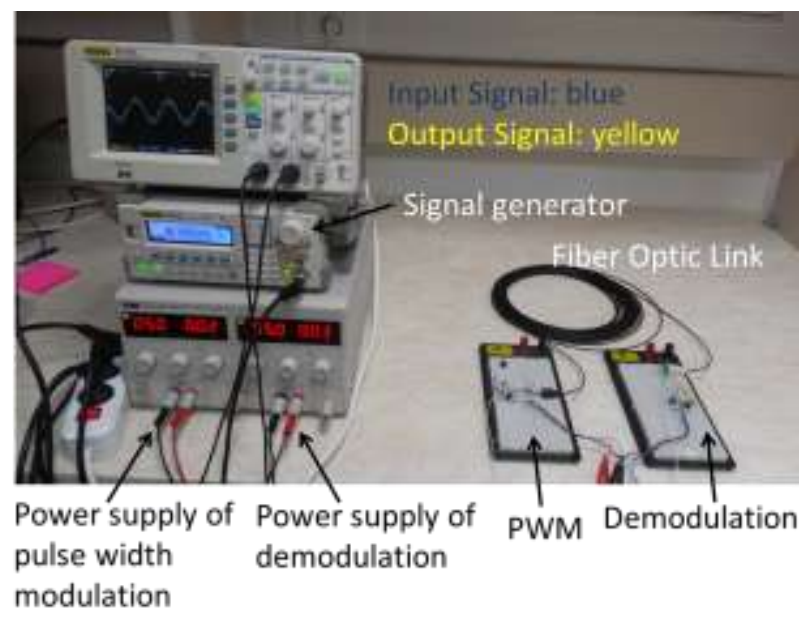

Fig. 5 Setup of the prototyping fiber optic data transmission system

\subsection{Weather Sensors}

Weather conditions can considerably affect the operation condition of insulators specifically under polluted conditions [1-2]. The leakage current activity on the insulator's surface is related to the current weather conditions, thus it is of great importance to monitoring them in combination to insulator's leakage current. The selection of weather sensors was determined by their compatibility with Arduino board which is based on the ATmega328, Atmel's microcontroller (Fig. 6). The temperature and humidity are measured by using DHT11 humidity and temperature digital sensor, succeeding temperature range from 0 to $+50^{\circ} \mathrm{C}$ with $2^{\circ} \mathrm{C}$ accuracy and humidity range of $20-90 \% \mathrm{RH}$ with $5 \% \mathrm{RH}$ accuracy. In addition, the barometric pressure is measured by using BMP180 sensor. The pressure range is from 300 to 1100 $\mathrm{hPa}$ respecting to altitudes from $+9000 \mathrm{~m}$ to $-500 \mathrm{~m}$ relating to sea level. The relative accurancy of barometric pressure measurement is $0.12 \mathrm{hPa}$ corresponding to $1 \mathrm{~m}$ altitude.

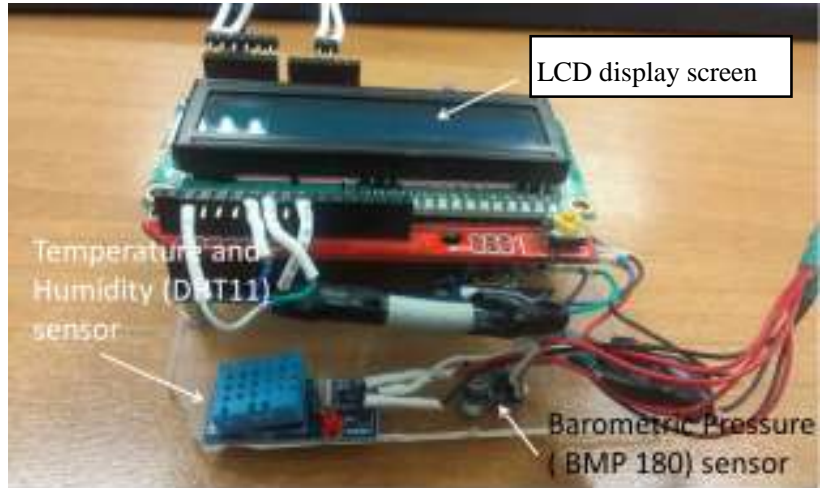

Fig. 6 Arduino board and weather sensors

\subsection{Data Acquiring System}

In order to process and control all the acquired data a microcontroller is used. As previously referred Arduino board was selected and it was programmed with its free of charge accompanied software. The Arduino board has 6 analog inputs with 10 bit resolution which mainly used for acquiring the leakage currents measurements. The weather sensors are connected to the digital channels of Arduino through $\mathrm{I} 2 \mathrm{C}$ bus.

The selection of this board is based on the easy opensource programming, the available number of analog and digital inputs-outputs ( $\mathrm{I} / \mathrm{O})$ and the scalability both of software and hardware. The processed data can be locally stored to an SD and SDHC card as text files. The communication of microcontroller and SD card is achieved through SPI protocol. These data are available locally but also the user can download them from internet due to the fact that Arduino GSM shield gives the ability of remote access to the stored data. Considering the operation of GPRS wireless network, it is able to live monitor the insulator condition. In addition it is able to send alarms or e-mails and warnings for possible faults, contributing to the maintenance of power networks.

\section{Conclusion}

The monitoring of the installed high voltage insulators is of great importance for the reliable operation of power networks. Until now the commercial monitoring devices face a lot of disadvantages related to high cost, lack of upgrades and limited number of motoring channels. The proposed insulator monitoring kit due to its low cost and its advantages can cover the advanced monitoring demands of power utilities. The easy installation, the open-source code software, the autonomous power supply and the easy modification of its operation according to the power utility needs are some of main advantages. The preliminary setup of the fundamental structure of the 
insulator monitoring kit project gives encouraging results in laboratory basis. Certainly the laboratory system must be further advanced both in software and hardware in order to be installed in field conditions.

\section{References}

[1] CIGRE TF 33.04.07, "Natural and artificial ageing and pollution testing of polymeric insulators", No.142, 1999.

[2] IEC TS 60815, "Selection and dimensioning of high voltage insulators intended for use in polluted conditions", 2008.

[3] R. Hackam, "Outdoor HV composite insulators", IEEE Transactions on Dielectrics and Electrical Insulation, Vol. 6, No. 5, pp. 557-585, 1999.

[4] K. Siderakis, D. Pylarinos, E. Thalassinakis, E. Pyrgioti, I. Vitellas, "Pollution maintenance techniques in coastal high voltage installations", Engineering, Technology \& Applied Science Research, Vol. 1, No. 1, pp. 1-7, 2011.

[5] N. Mavrikakis, K. Siderakis, D. Pylarinos, E. Koudoumas, "Assessment of Field Aged Composite Insulators Condition in Crete", 9th International Conference on Deregulated Electricity Market Issues in South Eastern Europe, Nicosia, Cyprus, 25-26 September, 2014.

[6] D. Pylarinos, K. Siderakis, E. Koudoumas, E. Thalassinakis, "Polymer Insulators and Coatings in the Cretan Power System. The Transmission Line Case", 9th Mediterranean Conference on Power Generation, Transmission Distribution and Energy Conversion, Athens, Greece, 2-5 November, 2014.
[7] N. Mavrikakis, K.Siderakis, E. Koudoumas, "Assessment diagnostics of the functionality of composite insulators operating in the $150 \mathrm{kV}$ power network of Crete", 30th Panhellenic Conference on Solid-State Physics and Materials Science, Heraklion, Crete, Greece, 21-24 September, 2014.

[8] N. Mavrikakis, K. Siderakis, P. N. Mikropoulos, "Laboratory Investigation on Hydrophobicity and Tracking Performance of Field Aged Composite Insulators", 49th International Universities' Power Engineering Conference (UPEC), 2-5 September 2014, Cluj-Napoca, Romania.

[9] D. Pylarinos, N. Mavrikakis, K. Siderakis and E. Thalassinakis, " $R \& D$ in TALOS High Voltage Test Station: A Distributed Approach on Insulator Monitoring Systems", 3rd Panhellenic Conference on Electronics and Telecommunications, Ioannina, Greece, May 8-9, 2015.

[10] D. Pylarinos, K. Siderakis, E. Thalassinakis, I. Vitellas, E. Pyrgioti, "Recording and managing field leakage current waveforms in Crete. Installation, measurement, software development and signal processing”, ISAP 16th International Conference on Intelligent System Applications to Power Systems, Hersonissos, Crete, Greece, September 25-28, 2011.

[11] D. Pylarinos, K. Siderakis, E. Thalassinakis, "Comparative Investigation of Silicone Rubber Composite and RTV Coated Glass Insulators Installed in Coastal Overhead Transmission Lines", IEEE Electrical Insulation Magazine, Vol. 31, No. 2, 2015. 